\title{
REVISIÓN DE LITERATURA: Breve nota sobre los primeros aportes de la historia a la teoría de la tributación
}

\author{
Diana Lizette BECERRA PEÑA \\ Aurea ARELlANO CRUZ \\ Patricia GUTIÉRREZ MORENO \\ Universidad de Guadalajara y Consejo Nacional de Ciencia y Tecnología, México \\ (Doctorado en Estudios Fiscales)
}

Received: 08/06/2016
Accepted: 02/07/2016

Resumen: Este ensayo ofrece una breve historia y evolución de los modelos que integran el pensamiento económico, de manera que se consiga ubicar aquellas aportaciones que han contribuido a la formación del aspecto tributario. El documento se desarrolla bajo una metodología de corte cualitativo, como un estudio descriptivo de tipo documental y está dividido en apartados de acuerdo al conjunto de ideas económicas que predominaban durante las diferentes etapas: la antigüedad en la Edad Media, el mercantilismo, los fisiócratas, Adam Smith y David Ricardo; finalmente se cierra con una breve sección de conclusiones.

Palabras clave: pensamiento económico, Edad Media, mercantilismo, fisiocracia, David Ricardo, Adam Smith, tributación

\begin{abstract}
This paper provides a brief history and evolution of models that integrate economic thought, so that they get to place those contributions that have contributed to the formation of the tax aspect. The document is developed under a qualitative methodology, as a descriptive study documentary and is divided into sections according to the set of economic ideas that prevailed during different stages: from the antiquity to the Middle Ages, mercantilism, physiocrats, Adam Smith and David Ricardo; it finally closes with a brief conclusion section.
\end{abstract}

Keywords: economic thought, Middle Ages, mercantilism, physiocracy, David Ricardo, Adam Smith, taxation.

JEL Classification: B10, B20, H20

\section{Introducción}

La historia del hombre no es, en realidad, sino la historia de la vida social, por primitivas que hayan sido las primeras manifestaciones. Es preciso indicar que las relaciones sociales en que se encuentra inmerso el ser humano, además de revestir determinadas formas, manifiestan la presencia de contenido, del cual deriva la trascendencia de unas y otras; entre las más inmediatas encontramos a las relaciones primarias, verdaderas necesidades, prevaleciendo definitivamente las económicas.

El homo oeconomicus se enfrenta, desde siempre, a la imperiosa satisfacción de sus necesidades vitales, en función de la cual desarrolla actividades encaminadas a la obtención de los bienes y servicios que requiere y a medida que la relación social se desarrolla y se hace más compleja, nos encontramos con lo que Stammler denomina "economía social", dentro de la cual la cooperación entre los individuos se hace imprescindible, directa o indirectamente.

Efectivamente ninguna colectividad, ni mucho menos ningún hombre aisladamente considerado, pueden o han podido satisfacer todas sus necesidades de carácter económico; hoy día, ni siquiera los países más ricos con todos los satisfactores que requieren de manera absoluta, motivo por el cual a lo largo de la historia humana siempre se ha presentado la necesidad del intercambio.

Podemos asentar entonces que la actividad económica se ha desarrollado siempre en el seno del conglomerado social, al encontrarse el hombre inmerso dentro de este, al margen de necesidades económicas individuales que hayan podido satisfacerse de manera particular y fuera del contexto social. El carácter recíproco de la relación social se manifiesta de igual forma en la relación económica de interdependencia. 
Esta actividad económica se ha visto reflejada desde las civilizaciones más antiguas; sin embargo no es hasta la Edad Media donde surgen las ideas que servirían como precedentes para las diferentes corrientes del pensamiento económico. Al terminar este periodo en el siglo XIV con hambrunas y pestes reiteradas que marcan el fin de una era, tales eventos sirvieron para que los supervinientes acumularan capital y para la modificación en la oferta y demanda de la época, así como para que el descubrimiento de un nuevo continente que reconfigurará toda la actividad económica.

Gracias al incremento de la actividad mercantil entre los siglos XIV y XV surge una nueva concepción de la economía donde se postula que esta tiene como fin el aumento de la riqueza, la cual depende del comercio y buenas prácticas, y que al final se verá reflejada en una acumulación de metales preciosos; con ello se da paso a la etapa mercantilista del pensamiento económico, cuando surge la imposición de aranceles al comercio exterior, a la navegación y al tránsito entre provincias.

Dentro del pensamiento económico, la escuela fisiocrática surge a mediados del siglo XVIII en Francia, y en opinión de algunos autores como la precursora de la economía moderna y como una reacción a las políticas restrictivas del mercantilismo, fue la primera en reflexionar sobre la actividad económica y en explicarla como un todo considerando a la tierra como la única fuente de riqueza de las naciones.

Refutando las ideas mercantilistas de que la riqueza de una nación se mide por el tamaño de su tesoro, y que la agricultura no solamente es la generadora de excedentes en la economía que defendían los fisiócratas, Adam Smith, a través de su tratado de economía titulado Investigación sobre la naturaleza y las causas de la riqueza de las naciones, publicado en marzo de 1776, describe cómo la fuerza de trabajo y su especialización en la industria eran las que generaban mayor riqueza económica, capaces de lograr el máximo interés personal como el de la sociedad en general.

A diferencia de los fisiócratas, las ideas tributarias de Smith proponían un impuesto múltiple y no único, que derivaba de la división del trabajo y aplicable a los salarios, las utilidades y la renta. Aunque quedó claro que este autor no confiaba mucho en gravar las utilidades por la libertad que tenía el dueño de retirarlas, sí consideraba gravoso que se intentara trasladar el impuesto a los consumidores, y concluyó que el impuesto mejor aplicado era el de la renta de la tierra.

Las aportaciones teóricas y leyes publicadas en su libro Principios de Economía Política y Tributación, publicado por primera vez en 1817, relativos al estudio sobre el valor, la renta, la utilidad, los salarios, el comercio exterior y los impuestos, además de su aporte a la consolidación de una teoría de la economía política aseguraron un lugar en la historia económica al inglés David Ricardo; quien, junto con varios contemporáneos como Malthus, Stuart Mill, Trower, Tooke entre otros, sentó las bases y aportaciones claves en el estudio de la economía; por citar algunos ejemplos, elementos como la teoría clásica de la renta, el principio de la población y la doctrina del fondo salario. En este contexto, el conocimiento de los principios de economía de Ricardo es fundamental para entender el devenir en la construcción de la teoría económica y en la construcción de respuestas a los problemas económicos del qué, cómo, cuánto y para quién producir.

En el presente ensayo se ofrece una breve historia y evolución de los primeros modelos que integran el pensamiento económico hasta el modelo ricardiano, de manera que se consiga ubicar aquellas aportaciones que han contribuido a la formación del aspecto tributario; el documento se divide en apartados de acuerdo al conjunto de ideas económicas que predominaban durante las diferentes etapas: la antigüedad en la Edad Media, el mercantilismo, los fisiócratas, Adam Smith y David Ricardo; finalmente se cierra con una breve sección de conclusiones.

\section{La Edad Media}

Es imposible pretender analizar el pensamiento económico de la Edad Media sin antes señalar algunos de los aspectos más relevantes de las civilizaciones que en la edad antigua florecieron y dieron pie a la época medieval; sin estas instituciones sería imposible entender los eventos que sucedieron en la Edad Media, pues todavía algunas de ellas siguen vigentes. 


\section{Los profetas}

En el texto más influyente de todos los tiempos, la Biblia, específicamente en el Antiguo Testamento, se advierte como se transformó de un régimen de propiedad comunal y de actividad económica rudimentaria hasta llegar a una sociedad estratificada de castas. La acumulación de riquezas se aprecia en el "Libro de Reyes" pero de manera clara en los señalamientos de diversos profetas como Jeremías e Isaías, quienes aluden a una profunda división entre ricos y pobres. La justicia es un valor relacionado con lo divino, por lo que se esperaba que Dios se encargara en redistribuir la riqueza; se condenaban los excesos de los comerciantes y usureros.

\section{Los griegos}

La economía ética de los griegos es incompleta y rudimentaria, las ideas económicas surgen incidentalmente en libros como el de Jenofonte "Oeconomicus", que es un estudio sobre la administración del hogar, Hesíodo en su obra "Los trabajos y los días", se ocupó del trabajo y la propiedad rural; en las Leyes de Solón se exigió que los ciudadanos realizaran actividades productivas y condenaron la ociosidad. El mismo Jenofonte en su obra "Como aumentar las rentas en Atenas" sostuvo que los comerciantes debían ser tratados en equitativamente. El pensamiento económico griego está representado en las escuelas de los sofistas, que señalan al individuo en rebeldía con el estado y los socráticos que defienden al Estado y esbozan un socialismo autocritico.

\section{Roma}

El interés por cuestiones económicas se manifestó hasta el final del imperio reiterando las ideas griegas, su mayor aportación fue el Derecho Romano, que ha servido para la base de las doctrinas e instituciones legales del capitalismo.

\section{Edad Media}

La expresión Edad Media creación del humanismo italiano (Lomba, 1997, pág. 8); es un periodo comprendido entre la caída del imperio romano de Occidente (año 476 D.C.) y hasta la toma de Constantinopla por los turcos, es decir la caída del Imperio Romano de Oriente (año 1453 D.C.), por lo que abarca un periodo aproximado de 1000 años. Su origen tiene como preámbulo la crisis del Imperio Romano del Siglo III, en la que existió hiperinflación en el imperio causados por la devaluación de la moneda, lo que sucedía cuando el Emperador de turno reducía la cantidad de oro y plata al momento de acuñar las monedas, además de las constantes invasiones de los pueblos barbaros que limitaban el crecimiento del imperio situación que afectaba el modelo del producción esclavista de aquel entonces, donde la fuerza del trabajo no le pertenecía a los trabajadores por lo tanto no deben ser retribuidos.

Los dos predecesores de modo de producción feudal fueron naturalmente el modo de producción esclavista, ya en trance de descomposición y sobre cuyos cimientos se había levantado todo un imperio, y los deformados modos de producción primitivos de los invasores germanos que sobrevivieron en sus propias tierras tras conquistas bárbaras. Estos dos mundos radicalmente distintos habían sufrido una lenta desintegración y una silenciosa interpenetración en los últimos siglos de la antigüedad.

El último periodo del Imperio Romano y las rudas costumbres de los germanos, dieron origen a la estructura social de la Edad Media que dividió a la sociedad en señores y siervos. Los juicios sobre esta época, han sido contradictorios, muchos historiadores lo ven como un periodo de estancamiento y oscurantismo. La caída del imperio romano significó un retroceso en muchos órdenes, la cultura, la comunicación por el abandono de las carreteras romanas, el comercio y la economía que redujeron su volumen para concentrarse en algunos puntos dando así vida a los feudos (Astudillo, 2007).

El feudo como unidad económica de las relaciones sociales y de producción, entre el señor feudal y sus siervos, se puede entender como un do ut des de protección a cambio de trabajo y sumisión. En la Edad Media los vasallos, los aldeanos y los siervos de un feudo otorgaban prestaciones personales y económicas al señor feudal con justificación en la protección que éste les brindaba. Curiosamente, en esta época nace, en el plano filosófico, el caldo de cultivo que redundará en el principio de la capacidad económica (Domínguez, 2008). 
El feudalismo fue un modo de producción dominado por la tierra y por la economía natural, en el que ni el trabajo ni los productos del trabajo eran mercancías. El productor inmediato, -el campesino- estaba unido a los medios de producción -la tierra- por una relación social específica. Los campesinos que ocupaban y cultivaban la tierra no eran sus propietarios.

La propiedad agrícola estaba controlada privadamente por una clase de señores feudales, que extraían un plus producto del campesinado por medio de relaciones político-legales. Está cuestión extraeconómica, que tomaba la forma de prestaciones de trabajo, rentas en especie u obligaciones consuetudinarios del campesino hacia el señor, se ejercían tanto en la reserva señorial, como en las tenencias cultivadas por el campesino. Su resultado era una amalgama jurídica de explotación económica con autoridad política. (Perry, 1979)

Sin embargo, el modo de producción feudal fue el primero que le permitió un desarrollo autónomo en el marco de una economía natural agraria. Las paradigmáticas ciudades medievales de Europa, que ejercían el comercio y la manufactura, eran comunas autogobernadas, que gozaban de una autonomía corporativa, política y militar. Fue preciso que transcurrieran varios siglos para que resurgiera la vida económica de Europa y las universidades de París, Oxford y Cambridge.

El cristianismo se entronizó y prácticamente dominó a la población para el año 1,000 d.C. Fue entonces cuando la Iglesia se convirtió en el principio unificador de la sociedad medieval tajantemente dividida en clases y grupos sociales, adquiriendo enorme poder espiritual y material.

El estudio económico formó parte de las enseñanzas morales del cristianismo. El mundo medieval influido por la Iglesia, ordenó bajo el espíritu de modelación todas las relaciones humanas, y así surgieron los conceptos del justo precio y justo salario, además de los gremios como organización del trabajo artesanal (Astudillo, 2011).

Una generación de pensadores ocupa el primer plano, entre los cuales sobresalen Abelardo, Alberto Magno, Guillermo de Ockhman, Roger Bacon, y sobre todo Santo Tomás de Aquino, quien escribió "La Suma Teológica" (Astudillo, 2011); este último, nos hizo una distinción al expresar que si bien la propiedad no ha sido impuesta por el Derecho natural sí es conforme a él. No admitió los derechos ilimitados que el Derecho Romano confería al propietario y aceptó la distinción aristotélica entre el poder de adquisición y administración.

Alberto Magno pretendió desarrollar la idea del justo precio indicando que debían cambiarse mercancías. Santo Tomás de Aquino sustentó una vaga teoría del valor del cambio a base del costo de producción. "Precio justo es un precio tal que corresponde a estas dos condiciones: la que permite al productor vivir decorosamente con el producto de su actividad y, segunda que impide poner a ración al consumidor".

Las relaciones de capital y de trabajo fueron minuciosamente reglamentadas a través de los gremios, agrupaciones de artesanos del mismo oficio sujetas a rigurosas normas sobre el ejercicio del profesional, relaciones internas entre sus miembros. Los gremios, por lo menos en los primeros siglos de su existencia, ejercieron una influencia bienhechora en la sociedad medieval.

Otra de las cuestiones que interesó a los escritores de la Edad Media, fue la relativa a la moneda. Nicolás de Oresme, Obispo de Lisieux, quien escribió una obra titulada "Del origen. Naturaleza, Derecho y Mutaciones de las Monedas", en la cual defendió las más sanas prácticas monetarias, explicó la misión económica y naturaleza de la moneda, la injusticia de que los príncipes la alteraran y sus nefastos efectos en la economía.

Las ideas económicas de la Edad Media, pueden encontrarse en las siguientes corrientes de pensamiento:

a) El Derecho canónico o eclesiástico, elaborado por la Iglesia a base de la aplicación a los problemas y procedimientos de la Iglesia del antiguo Derecho civil romano, codificado por Graciano, un sabio monje en 1142.

b) El Escolasticismo representó el esfuerzo de los teólogos para fusionar la filosofía griega, en especial la de Aristóteles, con la doctrina cristiana (Astudillo, 2011).

\section{El Mercantilismo}

La corriente mercantilista tiene sus inicios durante un periodo intervencionista, que tuvo presencia durante la época en que surge el capitalismo y previo a la Revolución Industrial. El concepto 
de mercantilismo se atribuye a Mirabeau (Guzmán, 2009), quien lo emplea para explicar aquellas ideas económicas que predominaban en el periodo que va del siglo XVI hasta la mitad del siglo XVIII.

Las condiciones para el desarrollo del mercantilismo surgen de manera desigual, se derivan de los descubrimientos geográficos, de la consecuente apertura comercial de las rutas marítimas y de la corriente de metales preciosos provenientes de Europa.

Durante este periodo nace el Estado-nación moderno, que comienza en Italia, le sigue en España, Portugal, Francia e Inglaterra (Izquierdo, 2007). Se observa un gran crecimiento económico, se comienza a hablar de términos como políticas y normas económicas. Tras la evolución del mercantilismo se emplean otros apelativos como sistema mercantil, Colbertismo en Francia, Cameralismo en Alemania.

Se fomenta el uso del dinero, al punto de jugar un papel protagónico dentro de la economía, debido a que todos lo necesitaban. En primera instancia les dotaba de poder para dar fin a las guerras, así como para sufragar los gastos de los nuevos Estados. Constituía el sostenimiento del aparato burocrático de los funcionarios públicos, además de ser el medio de pago en los diversos estratos sociales: los señores feudales para las deudas, la nobleza para los objetos lujosos y los más humildes para el tributo e intereses a usureros (Izquierdo, 2007).

El comercio a larga distancia tuvo un crecimiento, lo que llevo a adquirir colonias de ultramar y a la descomposición del feudalismo. Entre las reglas propuestas por Von Hornick, fundador del cameralismo (Ekelund \& Hébert, 2005, pág. 44) se señala que deberán dificultarse las importaciones de bienes extranjeros siempre que sea posible, además indica que deberán bloquearse toda importación de bienes que ya existan de manera suficiente dentro de la nación, estableciendo así los primeros antecedentes sobre las regulaciones al comercio internacional.

Por su parte, España se encargó de frenar el desarrollo económico de la Nueva España. Dado que se trataba de una colonia que le pertenecía, se estableció que únicamente podría realizar el intercambio de mercancías con la metrópoli (Gómez, y otros, 2011).

De lo anterior, se destaca que gracias a la implementación de normas para el tráfico de bienes también se consiguió la unificación del territorio, con lo que se pasó a eliminar todo rastro del feudalismo que entorpecía este proceso.

Los intereses económicos del poder del Estado constituían el objetivo primordial de la política económica de los mercantilistas, dejando de lado el bienestar social, a diferencia de lo que ocurre hoy en día.

En el caso de la Nueva España con la fundación de Veracruz, España impuso el impuesto denominado quinto real, con el que una quinta parte del botín conquistado le correspondía al rey, otra parte igual era destinada al conquistador (Cortés) y el resto era distribuido entre los soldados que acompañaban a este último (Gómez, y otros, 2011).

Los mercantilistas pretendían incrementar su enriquecimiento por medio de la riqueza de las naciones vecinas. Es así como durante la etapa inicial del mercantilismo surge el concepto del sistema monetario ${ }^{1}$, donde el poder se traducía en dinero, la economía debía conservarlo y acumularlo, ubicando al comercio exterior como su principal canal de afluencia (Izquierdo, 2007), sentando así las bases del capitalismo a través del flujo de dinero. Se trataba de la apropiación de la riqueza que ya existía, a expensas de otras naciones, en lugar de enfocarse a la producción de ella (Míguez, 2009).

El mercantilismo se sustenta bajo la idea de que una sociedad se cimienta en la existencia de una ley que por naturaleza la gobierna. El impulso del comercio exterior llevó a la creación de gravámenes a los buques y a las mercaderías, tanto al entrar como al salir, así como por la actividad de carga y descarga de las mismas; además de exigir el pago de un impuesto por el paso de mercancías entre provincias, así como el pago de un derecho de tránsito denominado peaje (Gómez, y otros, 2011).

Dicho lo anterior, se percibe una mayor participación de la Hacienda Pública con el nombramiento de tesoreros, así como la implementación de algunos impuestos extraordinarios derivados de las necesidades de las diferentes colonias.

\footnotetext{
${ }^{1}$ Para Marx, el mercantilismo constituye una variante del sistema monetario. Consultar su obra "Contribución a la crítica de la economía política", para profundizar en dicha cuestión.
} 
Aparece la cuestión de la balanza comercial durante la etapa denominada como mercantilismo desarrollado (Izquierdo, 2007), con la llamada "balanza de comercio multilateral" (Guzmán, 2009) que muestra los antecedentes de lo que hoy conocemos como balanza de pagos, y que se conformaba por la expresión de débitos y créditos.

A grandes rasgos, el mercantilismo surge de una serie de ideas y propuestas de políticas públicas con tintes económicos, como la intervención del Estado, la acumulación de metales, el establecimiento de aranceles al comercio exterior, el fomento de la industria doméstica, el financiamiento de viajes de exploración, la conquista y surgimiento de colonias y la balanza de pago favorable (Borgucci, 2011).

Los principios mercantilistas, donde los Estados nacionales basaban su actividad económica y política en el enriquecimiento que se obtenía por medio de la posesión de metales, la actividad colonial y el comercio de tipo monopolístico, dan pie al nacimiento de la Economía Política como ciencia (Míguez, 2009).

\section{Los fisiócratas}

Los fisiócratas creían en la existencia de leyes emanadas de la naturaleza y que era la tierra la fuente esencial de las riquezas utilizadas por el hombre, y consideraban preeminentemente a la agricultura sobre las demás actividades económicas. El fundador de la escuela fue François Quesnay (1694-1774), un economista y médico de cabecera en la corte del rey Luis XV, se interesó por la economía y escribió entre 1756 y 1757 varios artículos de la materia para su obra que ha sido considerada de mayor relevancia, el Tableau Économique (Cuadro económico, 1758), donde Quesnay describe lo que consideraba que era la ley natural de la economía.

Entre las principales teorías propuestas por Quesnay que hicieron suyas los fisiócratas están: el orden natural, su Cuadro económico, el laissez-faire, el producto neto, la propiedad territorial y el impuesto único (Gutiérrez, 2004).

\section{El orden natural}

Este aspecto consideraba que las sociedades humanas estaban regidas por leyes naturales establecidas por Dios y que los individuos debían conocerlo y conformarse a él, por lo que se entienden como leyes universales e inmutables. Se establecen dos funciones principales de los gobernantes; una, es guardar el orden natural y la propiedad, y la segunda, es realizar los trabajos públicos. Los aspectos básicos del orden natural eran el derecho a disfrutar de los beneficios de la propiedad, el derecho a trabajar y el derecho a la libertad, relacionado con la libertad de los demás a perseguir su interés personal. En este sentido, los fisiócratas explicaban que la sociedad humana debía estar regida por leyes naturales que no podían ser modificadas por las leyes positivas del Estado (Gutiérrez, 2004).

\section{El Cuadro Económico (Tableau Économique)}

La obra Quesnay fue publicada en 1758 en su versión original era un cuadro numérico que representaba en forma de zigzag los flujos de renta agregada entre las diversas clases socioeconómicas y proponía demostrar dos cosas: la manera en que el producto neto circulaba entre esas clases y cómo se reproduce todos los años. Para tener un buen manejo del capital proponía evitar que existieran ocho obstáculos: 1. Malos impuestos, que graven el capital de los agricultores, 2. Costo excesivo de la recaudación de impuestos, 3. Excesivo lujo en el ornato, 4. Exceso de gastos legales, 5. Falta de exportación de materias primas, 6. Falta de libertad en el comercio interior de materias primas y en el cultivo, 7. Malos tratos a la gente del campo, 8. Que el producto neto anual no vuelva a la categoría de gastos productivos.

Según el modelo de Quesnay, la economía se divide entre tres clases o sectores sociales:

1. Una clase productiva, integrada por agricultores. Esa clase productiva es la que mediante el cultivo de la tierra hace renacer las riquezas anuales de la nación. Los gastos productivos se emplean en la agricultura, en los prados, pastizales, bosques, minas, pesca, etc., para perpetuar las riquezas en granos, bebidas, madera, ganado materias primas para artículos manufacturados. Asimismo, dicha clase hace las inversiones de los gastos de los trabajos de la agricultura y paga anualmente las rentas de los propietarios de los terrenos. 
2. Una clase estéril, compuesta por comerciantes, fabricantes, criados y profesionales, es decir, constituida por todos los ciudadanos que se dedican a servicios y trabajos distintos de la agricultura. Los gastos estériles se hacen en mercancías manufacturadas, alojamiento, vestido, intereses del dinero, costos del comercio, productos extranjeros, etcétera.

3. Una clase propietaria, que incluye a los terratenientes y a los que posean cualquier título de soberanía de cualquier tipo. La clase de los propietarios abarca al soberano, los propietarios de los terrenos y los que perciben el diezmo. (Gutiérrez, 2004, pág. 89).

En el Tableau Économique, Quesnay hizo el primer esfuerzo para explicar el fenómeno de la circulación de la riqueza en un país y el primero en proponer el establecimiento de un impuesto único y permanente sobre la tierra.

\section{Laissez-faire}

Es una expresión francesa que significa "dejad hacer" y se constituyó en la base de una doctrina económica que propugna por una política de no intervención del gobierno en los asuntos monetarios individuales o industriales, y defiende la libre competencia y las preferencias naturales de los consumidores como principales fuerzas que permiten alcanzar la prosperidad y la libertad. Esta doctrina surgió a finales del siglo XVIII como una reacción ante el mercantilismo mediante el cual se desarrolló el control nacionalista de los gobiernos sobre los impuestos y el comercio. Los fisiócratas incorporaron por primera vez la teoría del laissez-faire en su doctrina, que establecía que el gobierno no debía interferir en las relaciones comerciales.

Así los fisiócratas, además de ser promotores del orden natural, se constituyeron en forjadores del laissez-faire y sugerían que los Estados no debían interferir en los asuntos económicos, más allá de lo absolutamente necesario para proteger la vida y la propiedad privada.

\section{El producto neto}

Los fisiócratas consideraban que siempre hay una diferencia entre lo gastado y lo producido; esa diferencia es el aumento real de riqueza o producto neto, y solo existía en la agricultura, siendo la única fuente de los avances en el crecimiento de la economía rural y de las rentas del soberano, y por eso hay que acrecentarlo. La solución la encuentran en la libertad del comercio de los granos, en el interior y en el exterior. Según los fisiócratas, si se trata de establecer de dónde proviene el dinero para las Finanzas Públicas; la fuente es la agricultura, que es productiva porque crea la riqueza. La industria y el comercio son estériles; sus rentas brutas no exceden sus gastos, no proveen de nuevos elementos a sus productos.

\section{La propiedad territorial}

La concepción fisiocrática de la propiedad territorial mostraba la diferencia entre un programa de gobierno que impulsara y preservara la producción privada, y los resabios de la autoridad feudal (Gutiérrez, 2004, pág. 96).

\section{El impuesto}

Quesnay opina que la agricultura es la única actividad que produce una renta (producto neto); para hacer frente a los gastos de la nación se deben establecer impuestos y al ser el producto neto el único ingreso auténtico, también debe ser la única riqueza sometida a impuestos. Propone que tanto por la sencillez como por la justicia y la economía, los impuestos se cobren únicamente en su origen, por lo que debería establecerse un impuesto único (impót unique), sencillo y directo sobre la tierra, y éste no debería exceder de un tercio del produit net (Gutiérrez, 2004, pág. 98).

\section{Adam Smith}

El nacimiento de un nuevo pensamiento económico se gestó con la escuela clásica iniciada por Adam Smith en el siglo XVIII, considerado fundador de la ciencia económica por su tratado completo de Economía titulado "Investigación sobre la naturaleza y las causas de la riqueza de las naciones" publicado en marzo de 1776. Su trabajo de redacción lo inició en 1767 en su ciudad natal Kirkaldy. La claridad de sus ideas y el gran detalle con el que escribió su obra, la hi- 
cieron tan popular que en doce años la editaron cinco veces y se hicieron traducciones a distintos idiomas. Su tratado está dividido en cinco libros:

El primero se refiere a la división del trabajo (y, por lo tanto, al progreso tecnológico), la teoría del valor y la distribución de las rentas; el segundo trata del dinero y la acumulación; el tercero es una digresión breve y muy sugerente sobre la historia de las instituciones y la economía desde la caída del Imperio romano; el cuarto ilustra críticamente las doctrinas mercantilistas y los principios fisiocráticos; finalmente, el quinto se refiere a los gastos e ingresos públicos y, con carácter más general, al papel del Estado en la economía. (Roncaglia, 2006)

Esta escuela dejó de lado las investigaciones del mercantilismo en Inglaterra en cuanto a su política restrictiva, y la escuela fisiocrática en Francia respecto de la concepción de que la agricultura era la única actividad productiva que podía generar excedentes de dinero, explicando a detalle y con un lenguaje claro los factores que permiten a la industria generar mayores excedentes a través de la división del trabajo.

Smith publicó antes de su tratado de Economía una obra sobre Teoría de los sentimientos morales, que inspiraron algunos de los apartados de su tratado, donde expresaba que las conductas humanas responden naturalmente a seis motivaciones: 1) el egoísmo, 2) la conmiseración, 3) el deseo de ser libre, 4) el sentido de la propiedad, 5) el hábito del trabajo y 6) la tendencia a permutar y cambiar una cosa por otra (Pantoja, 2011).

Para Smith el individualismo y el naturalismo, concepciones propias de la época, son base para la espontaneidad y naturalidad de las instituciones económicas que son justas y ventajosas; es decir la actividad económica se mueve por el interés personal de los individuos y no por alguna voluntad superior a ellos. La espontaneidad da lugar a la división del trabajo, la moneda, la acumulación del capital, la teoría de la oferta y la demanda, entre otras (Pantoja, 2011). Así mismo, definió la división del trabajo como una preferencia de la naturaleza humana al intercambio de productos, razón por la cual cada quien debe contar con lo suficiente (mínimo vital) para estar en posibilidades de realizar dicho intercambio.

Un punto de coincidencia con los fisiócratas fue que el interés personal movía los negocios y el comercio, pues los individuos buscaban emplearse en el mejor trabajo que les aportara mayores beneficios de acuerdo a su interés no al de la sociedad; sin embargo, de una forma natural su decisión de emplearse impacta positivamente a la sociedad.

Smith... "intentó demostrar que era posible buscar la ganancia personal de forma que no sólo se pudiera alcanzar el objetivo individual, sino también la mejora de la sociedad" (Pantoja, 2011. pág.350). Razón de lo anterior es que estaba en contra de leyes o regulaciones que restringieran el interés personal natural y libre en todos los sentidos. De aquí que el liberalismo económico smithiano se basara en que cualquier obstáculo para el comercio o la libre empresa será un obstáculo para la división del trabajo y por ende para el bienestar de los ciudadanos y de la riqueza de las naciones.

El legado de Smith se centró principalmente en explicar los elementos que son determinantes en el estilo de vida de un país tendientes al progreso o al retroceso. De aquí que el nivel de vida dependerá de dos factores, la proporción de individuos empleados y su productividad. (Roncaglia, 2006)

De los cinco libros de que se compone el tratado de Smith uno lo dedica al papel del Estado en la economía, y en la parte II, lo dedica al tema de los tributos, sección que por su importancia consideramos necesario comentar derivado de las aportaciones que tuvieron en la época y de cuyas premisas se erige la necesidad del pago de impuestos

I. Los vasallos de cualquier Estado deben contribuir para sostener al Gobierno, a proporción de sus respectivas facultades, en cuanto les sea posible esta regulación [...] En la observancia o en la omisión de esta máxima consiste lo que llamamos igualdad o desigualdad de imposición [...]

II. El impuesto que cada individuo está obligado a pagar debe ser cierto y no arbitrario. El tiempo de su paga, la forma del pagamento, la cantidad que ha de pagarse, todo debe ser claro y llano e inteligible para el contribuyente y para cualquier persona. [...] La incertidumbre de la contribución es ocasión para la insolencia $[\ldots]$

III. Todo impuesto debe exigirse en el tiempo y del modo que sea más cómodo y conveniente a las circunstancias del contribuyente. [...] 
IV. Toda contribución debe disponerse, de suerte que de poder de los particulares se saque lo menos que sea posible sobre aquello, o a más de aquello que entra efectivamente en el Tesoro público del Estado. (Smith, 1794, libro V, capitulo II, parte II, pp. 187-191)

De la lectura completa de esta última fracción se hace explícito el principio de la eficiencia y eficacia en la utilización del gasto público ya que la recaudación deberá ser en términos reales más que lo que sale o le cuesta al gobierno el allegarse de recursos.

A diferencia de los fisiócratas, las ideas tributarias de Smith proponían un impuesto múltiple y no único, que derivaba de la división del trabajo y aplicable a los salarios, las utilidades y la renta. Aunque quedó claro que Smith no confiaba mucho en gravar las utilidades por la libertad que tenía el dueño de retirarlas y si consideraba gravoso el impuesto intentaría trasladar el impuesto a los consumidores, así que el impuesto mejor aplicado era al de la renta de la tierra.

Finalmente, entre otros temas como la espontaneidad de las instituciones económicas, la evolución económica de la población y el comercio, Smith construye una definición de los valores de uso y los valores de cambio, pero no logra introducir una teoría adecuada a los valores de cambio, lo que sí hace posteriormente David Ricardo, mediante la concepción teórica de los precios relativos.

\section{David Ricardo}

Para David Ricardo el principal interés en el tema económico era más un intento dialectico por comprender, entender y explicar las relaciones económicas de su época. Según advierte en su prefacio del libro de "Principios de Economía Política y Tributación", todo el producto se divide en las tres clases de la comunidad y las proporciones que posee cada una varía en las diferentes etapas de la sociedad, por lo cual afirmó que el problema económico será siempre un problema vinculado con las leyes que regulan la distribución.

Una de las primeras aportaciones a la comprensión de la Economía y su funcionamiento, la establece al identificar la existencia de tres factores de la producción tierra, trabajo y capital, y al señalar que la expresión de valor más primitiva es la del factor trabajo; también estableció que para cada factor hay una correspondencia en clases sociales que se apropian o son dueños de dicho factor, así, el factor tierra se vincula con la clase social terratenientes, el trabajo con los asalariados y el capital con los capitalistas o llamados empresarios. En suma, el producto de la riqueza se distribuye de la siguiente manera: en forma de renta para los terratenientes, en forma de salarios para la clase trabajadora y en forma de utilidades o ganancias para los capitalistas.

Sobre la teoría del valor, en la que inicia su libro de "Principios de Economía Política y Tributación", David Ricardo al igual que Adam Smith, distingue entre el valor de uso y valor de cambio, sin embargo para Ricardo el valor de cambio de un producto no se puede medir con solamente revisar la capacidad que este tiene para satisfacer una necesidad humana, y para resolver este tema propone dos clase de valor de cambio: valor natural y valor de mercado; el primero es el que se establecería sin la existencia de perturbaciones en los mercados, y el segundo se determina por la cantidad de trabajo empleado, el capital requerido y la escasez, donde este último elemento constituirá un aporte por demás significativo para el entendimiento del comportamiento de los mercados y la definición de los precios de las mercancías.

Para Ricardo, el valor dependerá de los cambios en la tasa de los salarios, pagados y la tasa de las ganancias recibidas suponiendo constante los costos relativos al trabajo. A pesar de que el autor reconoce como se da la distribución de la riqueza (renta, salario, ganancias), considera que el pago de la renta es un pago socialmente innecesario, en el sentido de que esta pueda producir la oferta disponible de tierra. Su concepto de valor radicó más en el tema del trabajo y en los costos reales del proceso productivo (trabajo y capital). Lo que lleva a concluir que en todo valor de cambio se dé la escasez o del trabajo.

Con referencia al tema de las utilidades David Ricardo señaló que la competencia tiene a establecer una tasa uniforme, atrayendo capitales a los negocios que rinden una tasa superior a la medida y apartándolos de los que dan utilidades inferiores a la medida, regla básica para la economía y que permite explicar porque Ricardo está a favor del libre cambio y de la no intervención del estado, excluyendo al factor tierra en la determinación del valor. 
No olvidar que el problema central de investigación de Ricardo es ver los cambios que se producen en la renta o riqueza en los diferentes factores tierra, trabajo y capital y el efecto de dichos cambios sobre la acumulación de capital y el crecimiento económico. Lo que le permitió concluir que la riqueza de su país, Inglaterra, no descansaría en la agricultura sino en el desarrollo adecuado del capital. Esto denota su crítica a los terratenientes y lo lleva a desarrollar una teoría sobre la renta de la tierra introduciendo para ello el concepto de los rendimientos decrecientes de la tierra, y el concepto de intensivo, conceptos de los que se valen la teorías marginalitas. Sobre el tema de la renta de la tierra, Ricardo afirma que toda la ganancia de la renta de la tierra es para el terrateniente quien no presta ningún servicio ya que las únicas causas que determinan la renta de la tierra es: 1) las diferencias de fertilidad, 2) las diferencias de la situación respecto al mercado, y 3) la diferencia en los rendimientos del trabajo y el capital.

Sobre su teoría de la distribución, David Ricardo sostenía que el problema económico era el de la distribución, o la forma en cómo se reparte la riqueza generada en el proceso productivo entre los factores de la producción. Para enfrentar este problema Ricardo formuló Leyes sobre la renta, los salarios y las ganancias, esto lo lleva a demostrar que los salarios y las utilidades no son consecuentes con la generación de riqueza pues se relaciona en forma inversa: si suben los salarios se reducen las utilidades y viceversa.

Una de sus principales preocupaciones es la tendencia a la baja de las utilidades y para ello propone el esquema de comercio exterior y da múltiples aportaciones en la teoría de los salarios, que por cierto busca contener o los considera causantes de la baja en las ganancias y beneficios del capital. Dice que el precio de la fuerza de trabajo debe ser aquel que le permita adquirir los productos necesarios para su sostenimiento, que se hace más difícil por el alza de los precios de los alimentos y en su libro señala que

la tasa utilidades no podrá ser incrementada a menos que sean reducidos los salarios y no puede existir una baja permanente de salarios sino a consecuencia de la baja del precio de los productos necesarios en que los salarios se gastan. En consecuencia, si la expansión del comercio exterior o el perfeccionamiento de la maquinaria hace posible colocar en el mercado los alimentos y productos necesarios al trabajador, a un precio reducido, las utilidades aumentaran. (Ricardo, 1973, p. 92)

Sobre el tema de los impuestos David Ricardo los consideraba como una porción del producto de la tierra y de la mano de obra de un país, puestos a disposición de gobierno, y que su pago proviene siempre del capital o del ingreso del país. Como todo buen empresario se manifiesta en contra de los impuestos y señala que

No existe impuesto alguno que no tenga tendencia a disminuir el poder de acumulación. Todos los impuestos inciden ya sea sobre el capital o sobre el ingreso. Si gravan al capital disminuirán proporcionalmente este fondo cuya magnitud viene siempre a regular la importancia de la industria productiva del país. De caer sobre el ingreso, o bien disminuye la acumulación o bien obligan a los contribuyentes a ahorrar la cantidad correspondiente al impuesto, disminuyendo su anterior consumo improductivo de artículos necesarios o de lujo. (Ricardo, 1973, pág. 115)

Ricardo sostiene que los impuestos causaran estos efectos en mayor grado o menor grado aún se consideren que no graban al capital o al ingreso, esto implica dos aportes importantes; primero que el pago de los impuestos es o puede ser trasladable a otros sujetos no obligados; y segundo el tema de incidencia impositiva. Para el autor, los impuestos no deberían de incidir sobre el capital puesto que, de hacerlo así, disminuirían los fondos destinados al sostenimiento de la mano de obra, y con ello se reduciría la producción futura del país. Finalmente analiza y revisa los tipos de impuestos de su época, como lo son los impuestos sobre productos primos, diezmos, impuesto predial, sobre el oro, sobre viviendas, sobre utilidades, sobre salarios, sobre artículos distintos del producto primo e impuesto de pobres.

\section{Conclusiones}

A partir de la revisión de literatura sobre la historia del pensamiento económico, podemos vislumbrar la transición que se da entre las diferentes etapas y las diversas concepciones sobre las 
cuales se sustentan las principales teorías económicas y su incidencia en el ámbito de la tributación.

Los mercantilistas son considerados los primeros en identificar la importancia de la política monetaria y de comercio exterior. Dicho lo anterior, el mercantilismo como doctrina económica se fundamenta en tres ideas; primero, que la economía tiene como finalidad la adquisición de riquezas; segundo, que esto solo podrá conseguirse a través de intercambios; y tercero que el Estado es el principal agente económico.

La política mercantilista resultó progresiva para la época en que se desarrolló. Consistía en una orientación nacionalista, donde la política económica tuvo tintes proteccionistas e intervencionistas y favoreció al surgimiento de las primeras grandes empresas capitalistas en el sector manufacturero (Izquierdo, 2007).

En este sentido, se sientan las bases de lo que conocemos como modelo de desarrollo; en un primer momento se trataba de un modelo de desarrollo hacia adentro, con la promoción del nacionalismo donde el crecimiento económico se centraba en el mercado interno; situación que prevalece dentro de los planes nacionales de desarrollo en la actualidad, con ello se busca la promoción de políticas de desarrollo productivo que sean afines a las capacidades productivas de cada una de las regiones, y que estas se integren a su vez con los mercados nacionales e internacionales; asimismo, el proteccionismo se intensifica en situaciones de crisis y escenarios de escasez ante riesgos financieros inminentes en el contexto internacional.

Posteriormente con las importaciones de materias primas que no se producían domésticamente libre de impuestos se observa un destacado precedente a la economía de libre mercado, traducido en tratamientos especiales e incentivos fiscales, como se observa hoy en día a través de la disminución y/o exención de impuestos temporales, aduanales y financieros, claramente visualizados en las denominadas Zonas Económicas Especiales (ZEE) en diversas regiones del mundo, principalmente en los países en desarrollo y que es empleado como un instrumento de política fiscal para la estimulación del consumo y la inversión como medios de clave para el desarrollo.

Otra de las principales contribuciones que los mercantilistas han hecho a la Hacienda Pública es el desarrollo de la balanza de pagos, nacional e internacional, con su llamada "balanza de comercio multilateral". Esto se complementa con la idea fisiocrática del producto neto, al tomar en cuenta el diferencial entre lo que se gasta y lo que se produce, lo que constituye un reflejo del incremento real de la riqueza de una nación.

El razonamiento de la escuela fisiocrática afirmaba que las sociedades estaban regidas por un orden natural y que el gobierno no debía intervenir en ellas, consideraban que cualquier acción que realizará el Estado sobre la economía sólo serviría para trabar el mecanismo o la forma en que funcionaba la sociedad, entendían que la agricultura era la única actividad humana que producía nueva riqueza, para ellos la industria o el comercio no favorecían la prosperidad de un país, la única clase productiva era aquella que estaba vinculada al trabajo de la tierra.

Dentro de los principales exponentes fisiócratas están Jean François Quesnay y Turgot, quienes explicaban que mientras más tierra y mayor producción agrícola tuvieran los pueblos serían considerados más ricos y más potentes.

Los principios fisiocráticos pretendían establecer un impuesto único sobre la renta de la tierra, suprimiendo todos los demás impuestos que agravarán al agricultor. Los fisiócratas consideraban que la riqueza circula entre tres grupos sociales: la clase productiva (los agricultores), la clase estéril (los artesanos y comerciantes) y los propietarios (la nobleza, el clero y los funcionarios). El Estado debe mantener este orden natural mediante tres reglas: el derecho a la propiedad, la libertad económica (el laissez faire, laissez passer) y la seguridad en el disfrute de esos derechos y libertades.

Derivado de lo anterior, se observa que otro de los aportes de la corriente fisiocrática, el laissez-faire ha sido uno de los más relevantes, esto en el sentido de optar por una política donde el Estado no intervenga y derivado del libre mercado apoyado del pleno empleo, lo que en parte se traduce hoy en día en un sector público que, bajo el enfoque de gobernanza, ha buscado y fomentado la asociación público-privada en la búsqueda de soluciones a grandes problemas sociales, así como para el desarrollo económico y social.

La obra fundamental realizada por Smith hace que sus aportaciones a la ciencia económica y política tengan trascendencia teórica y práctica en el mundo. Definitivamente sin las ideas de 
este gran economista y filósofo social no se hubiera llegado a desarrollar tan rápidamente el pensamiento económico ni se hubieran sentado las bases para las teorías de sus precursores.

Smith contribuye a los Estudios Fiscales de la actualidad al señalar que cada individuo debe contar con lo suficiente para estar en posibilidades de realizar un intercambio de productos, lo que hoy en día se conoce como mínimo vital. Asimismo, propone la aparición de un impuesto múltiple, a diferencia de los fisiócratas, que se aplique a los salarios, las utilidades y la renta, similar a los esquemas tributarios vigentes.

Aunado a lo anterior, y sin restarle mérito, otra de las grandes aportaciones de Smith han sido los principios de la eficiencia y la eficacia en la ejecución del gasto público, una preocupación que sigue vigente hasta nuestros días para la Hacienda Pública: hacer más con menos.

El pensamiento económico de David Ricardo contempla importantes aportes al estudio de las relaciones económicas en cuanto a los factores que la determina y la forma en cómo se distribuye la riqueza, esto le permitió elaborar una teoría general de valor, de la distribución y de la acumulación, además de desarrollar la teoría de comercio exterior en especial la de los costos comparativos.

Finalmente, Ricardo introduce elementos y conceptos importantes para el entendimiento económica como los son los factores la producción (tierra, trabajo y capital) que continúan vigentes y a los que se ha sumado la capacidad empresarial, el concepto de escasez, de los rendimientos decrecientes, entre otros, finalmente hace importantes aportes en el análisis tributario en cuanto a sus características y su incidencia económica.

\section{Bibliografía}

Astudillo, Pedro. 2007. Elementos de Teoría Económica. México, Porrúa.

— 2011. Lecciones de Historia del Pensamiento Económico. México, Porrúa.

Borgucci, Emmanuel. 2011. Vigencia de algunas de las ideas mercantilistas de Thomas Mun, Revista de Ciencias Sociales, 27(2), 359-374. http://www.redalyc.org/pdf/280/28022757014

Chamberlain, John. 2010. Las raices del capitalismo (extracto del prólogo). En J. Chamberlain, The roots of capitalism. Indianapolis, EE.UU., Libertad Fund Inc., 1-5.

Cuevas, Ricardo. 2009. Ética y economía en la obra de Adam Smith: la visión moral del capitalismo, Ciencia y Sociedad, XXXIV (1), 52-79.

Domínguez, César. 2008. Una Revisión al Concepto Jurídico-Tributario del Principio de Capacidad Económica. En Temas Selectos de Derecho Tributario. México, Porrúa, 1-40.

Ekelund, Robert y Hébert, Robert. 2005. Historia de la teoría económica y su método. México D.F., McGraw-Hill.

Gómez, Gerardo; Amézquita, Agustín; Hernández, José; Ramírez, María; Cortés, Juan; Delgado, Emilio y Márquez, Marcia. 2011. Tratamiento fiscal de las asociaciones en participación. S.1. Electrónica ed. www.eumed.net/libros/2011a/912/

Gutiérrez, Gabriel. 2004. Historia del pensamiento económico. México, Oxford University Press.

Guzmán, Miguel. 2009. El mercantilismo y la transición al liberalismo. En H. Del Río, T. Da Cunha, \& M. Vizcaíno, Ensayos sobre historia del pensamiento económico. Chihuahua, Cuerpo Académico "Derecho, Estado y Sociedad Democrática" Facultad de Derecho y Ciencias Sociales, UMSNH, 163.

Izquierdo, Consuelo. 2007. La economía política burguesa como ciencia: el mercantilismo y su contribución. Contribuciones a la economía, s.l, s.i. http://www.eumed.net/ce/2007c/ceia.htm

Lomba, Joaquín. 1997. La raíz semítica de lo europeo. Ediciones Akal, S.A. Madrid, España.

Míguez, Pablo. 2009. El nacimiento del estado moderno y los orígenes de la economía política. Nómadas. Revista crítica de Ciencias Sociales y Jurídicas, 22(2).

Pantoja, Gabriel. 2011. Instituto de Investigaciones Bibliográficas.s.l., s.i. http://www.paginaspersonales.unam.mx/files/698/Publica 20110921175115.pdf

Perry, Anderson. 1979. Transiciones de la Antiguedad al Feudalismo. Traducción de S. Juliá, México, Siglo XXI.

Ricardo, David. 1973. Principios de Economía Política y Tributación. México, Fondo de Cultura Económica. 
Roncaglia, Alessandro. 2006. La riqueza de las ideas. Una historia del pensamiento económico. Zaragoza, Prensas Universitarias de Zaragoza.

Smith, Adam. 1794. Investigación sobre el origen y naturaleza de la riqueza de las naciones. Traducción de Josef Alonso Ortiz. Valladolid, España. En la oficina de la viuda e hijos de Santander. Consultado en:

https://archive.org/stream/investigacinde04smitguat\#page/186/mode/2up 